\title{
A Study on the Working Performance of Dimming Methods for Single- and Multichip Power LEDs
}

\author{
İsmail Kıyak \\ Department of Electrical Education, Technical Education Faculty, Marmara University, 34782 Istanbul, Turkey \\ Correspondence should be addressed to İsmail Kiyak, imkiyak@marmara.edu.tr
}

Received 3 August 2012; Revised 17 September 2012; Accepted 17 September 2012

Academic Editor: Fahrettin Yakuphanoglu

Copyright () 2012 İsmail Kryak. This is an open access article distributed under the Creative Commons Attribution License, which permits unrestricted use, distribution, and reproduction in any medium, provided the original work is properly cited.

\begin{abstract}
Light emitting diodes (LEDs) have many positive features, such as long life, low power consumption, and high luminous efficacy. Consequently, they are very attractive for use in many applications. Also, the use of LEDs ensures energy savings. Power LEDs have increasingly been used for general lighting via multichip module technology. The output of power LEDs should be controlled to obtain life and illuminance values in catalog. In this study, the effects of different dimming methods are investigated for single-and multichip LEDs. To achieve this aim, pulse width modulation (PWM) and current variation (CV) dimming methods are applied to single and multichip power LEDs during ten stages of dimming. A current-regulated DC source is used for current variation (CV) dimming, and a driver designed by the researcher is used for pulse width modulation (PWM) dimming. Moreover, all of the applications are made for active and passive cooling. Finally, the results are compared.
\end{abstract}

\section{Introduction}

In the era of global warming and increased energy costs, efficiency and sustainable development are a key state development factor [1]. Over 2 billion people in the developing world have no access to electricity [2]. Economic development brings a growing search for electronic equipment, thereby significantly increasing power consumption. About $20 \%$ of the electricity consumed in the world is spent on residential and public lighting. Therefore, there is a demand for high-efficiency lamps [1]. Home power consumption has become an important part of energy consumption. In particular, the power consumption of lamps in a typical home is a factor that cannot be ignored [3]. Although an LED solution is still more expensive to implement, energy costs are reduced and the shortcomings of fluorescent technology can be addressed, including energy savings by dimming and color temperature control. According to the Optoelectronics Industry Development Association (OIDA), the cumulative energy savings for utilization of LED lighting in the United States alone could amount to an estimated 16.6 quads $(760 \mathrm{GW})$ of electrical energy by 2020 [4].
LEDs are semiconductor devices that emit photon energy (light) when an electrical current is passed through them [5]. Its many advantages over conventional light sources that were developed by improving luminous efficiency and integrating multichips within limited areas are unparalleled. Therefore, LEDs have been considered one of the most valuable light sources in 21st century [6,7]. High brightness light-emitting diodes (LEDs) are a promising technology for lighting. Due to rapid technological improvement, the illuminating efficiency of LED has reached $>100 \mathrm{~lm} / \mathrm{W}$ in commercial products and have demonstrated proven energy saving compared to traditional lightings, such as incandescent $(<20 \mathrm{~lm} / \mathrm{W})$, fluorescent $(<50 \mathrm{~lm} / \mathrm{W})$, and mercury $(<70 \mathrm{~lm} / \mathrm{W})$ lamps [8].

Recently, LED and its module have received increasing attention since they can be widely used in energy-saving lighting engineering such as indoor lighting, solar streetlight systems, or photovoltaic (PV)/wind hybrid road lighting systems [9]. There are many inherent advantages of LEDs over conventional lighting systems, for example, higher efficacy, increased lifetime (measured in tens of thousands of hours), ruggedness, environmental friendliness (no mercury or lead), compact size, and low operating voltages, which make 
them suitable for PV applications [10]. The development of efficient photovoltaic (PV) standalone systems requires advanced technology for PV cells and modules for high performance [11] but also the application of components or loads of use with low energy consumption [12]. However, at present, the heat fluxes of LED chips are more than $100 \mathrm{~W} / \mathrm{cm}^{2}$, and the thermal problem that results from heat generated within the LED itself is still a bottleneck that limits the stability, reliability, and lifetime of high power LED. Therefore, effective thermal design LED packages with low thermal resistance are critical to improve the performance of LED [13].

Thermal management is extremely important in improving the reliability and efficiency of LEDs for general illumination applications [14]. Therefore, it is critical for maintaining the expected LED lifetime and light output that thermal performance parameters be defined by design at the chip package and system level, which includes heat sinking methods and interface materials or methodology. As LED heat escalates, several key characteristics may become apparent, thus demonstrating the importance of LED thermal management. When thermal management of LED is not made continuously, a complete thermal runaway may occur as a result of the LED junction temperature [15].

Since the light output is a function of the device thermal conditions, no heat dissipation bottleneck is allowed to exist in the heat passage, especially for multichip LED modules. Efficient thermal dissipation is the key challenge for multichip LED modules. Obviously, substrates play an important role in the heat dissipation issue due to their low thermal conductivity. In the heat passage, copper an even aluminum nitride (AlN) submount is substituted for a sapphire submount, while a metal alloy eutectic is used to replace the silver paste. On the other hand, an Al-based substrate is also widely used because of its low cost, but its thermal dissipative ability is restricted by the dielectric layer. The thermal conductivity of an AlN-based ceramic substrate is as high as $180 \mathrm{~W} / \mathrm{m} \mathrm{K}$ and is an insulator. A combination of the feasible modeling properties of the current layer of the LTCC and the AlN-based ceramic substrate is considered a better choice for high-power LED packages, especially for multichip modules [16].

The driving electric current of LED chips is growing quickly in an effort to obtain more lumens. However, generally, nearly $80 \%$ of the input power is transformed into heat while the rest is transformed into light in the highpower LED chips. Therefore, during the effort to make LED brighter, LED chips will generate much heat. In order to meet illumination demands and reduce costs, LEDs have been packaged in multichip packaging modules [17]. LEDs can have their light emission controlled. This control is known as dimming, and the literature presents some dimming strategies. The most used strategies are the variation in the level DC and pulse width modulation (PWM). The variation in the DC level controls the luminous flux emitted by varying the DC current LED amplitude. However, PWM uses a square wave power supply for these devices; thus, the light flux is changed by varying the duty cycle of this signal [1].
In this study, the effects of different dimming methods are investigated to determine the operating performance of single and multichip power LEDs. The dimming process directly affects power LEDs' operation current. Also, an increase or decrease in operating current affects the working temperature of power LEDs. Moreover, this temperature changes the effective power of LEDs' illuminance values. In order to determine these changes, experiments were carried out for four different conditions. However, $3 \mathrm{~W}$ and $5 \mathrm{~W}$ single-chip power LEDs and $10 \mathrm{~W}$ and $15 \mathrm{~W}$ multichip power LED modules are used for the experiments without a reflector. Active and passive cooling experiments were carried out to investigate cooling effects on single and multichip power LEDs. A test box was designed to isolate experiments from external light and reflection.

\section{Multichip Power LEDs and Heat}

Semiconductor devices have broad applications, for example, as the light-emitting diodes (LEDs) [18]. In recent years, due to the rapid development of high power LEDs, thermal management and heat dissipation become essential [19]. Therefore, heat dissipation is an important issue in highpower LED lighting technology [20].

The number of defects responsible for nonradioactive recombination increases with temperature. Therefore, the junction temperatures of LEDs significantly influence reliability and durability. Accurate and reliable measuring techniques in LEDs' junction temperature are of primary importance in designing high-power LEDs. The chip sizes of LEDs are limited due to incremental wafer sizes. On the other hand, high power can be generated in LEDs by increasing the chip size or implementing the multichip scheme in a package. Although the thermal characterization of LED packages with a single chip is investigated, there are no reports about the thermal behavior of multichip schemes [21].

Figure 1 shows the schematic structures of LED packages with different numbers of chips. The main package structure is similar, but the number of chips is different [21]. The current challenges faced by solid state lighting are to increase total flux output of multiple high-power LEDs and to increase the lighting efficiency of each [3].

The thermal performance of multichip modules is different from single-chip modules due to possible nonuniformity in temperature. Research on the thermal characteristic of multichip LEDs is becoming a new topic. The results demonstrate that in multichip packaging, the dependence of the thermal resistance and junction temperature on the number of chips is stronger for the LED package [17]. The performance characteristics of LED light sources are directly dependant on a rated current and LED die junction temperature of $25^{\circ} \mathrm{C}$. Since the optimum operation temperature is above $25^{\circ} \mathrm{C}$ for most LEDs, the light output should be based on the anticipated operating temperatures [22].

The light output of LEDs decreases linearly depending on die junction temperature, as shown in Figure 2. Increases in LED die junction temperatures can result in increased power 


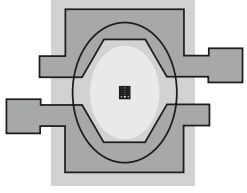

(a)

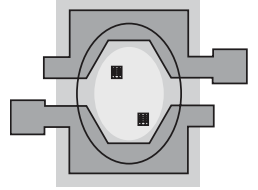

(b)

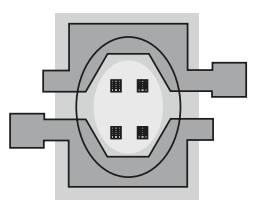

(c)

FIGURE 1: Schematic structures of high power LED with multichip package: (a) one-chip, (b) two-chip, and (c) four-chip [21].

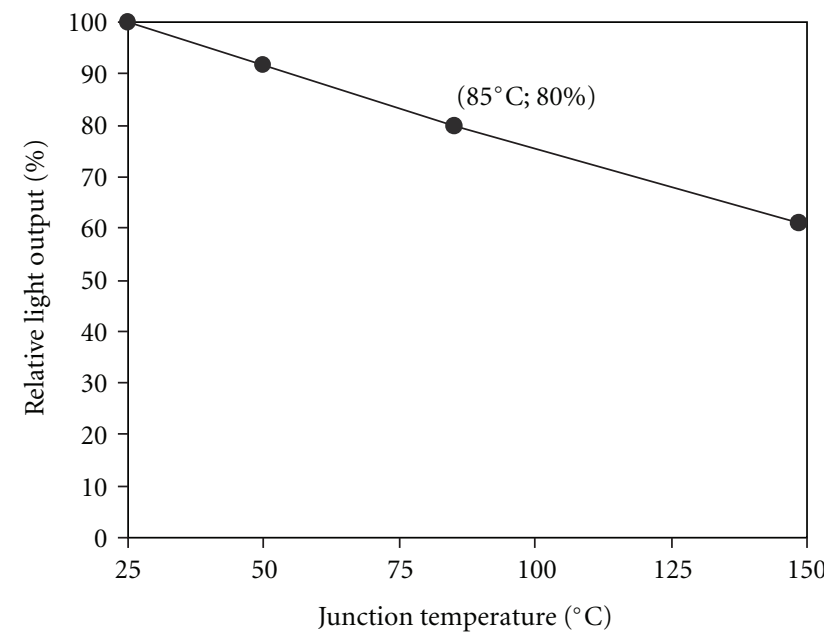

FIGURE 2: Relationship between temperature and light output [22].

dissipation or changes in ambient temperature. Accordingly, temperature effects are considered in the design [22].

\section{LED Dimming Methods}

LEDs can have their light emission controlled. This control is known as dimming, which is the most used technique. However, the most attractive strategies in the literature are varying DC levels and pulse width modulation (PWM) [1].

The waveform of the current in the LED using the two dimming methods is shown in Figure 3. The main difference between the two dimming methods is that the first one imposes a linear variation of the value of the continuous current amplitude, while in PWM methods, the current introduced to the LED is a rectangular wave with a varied duty cycle. In both cases, the average current supplied to the LED is the same, $50 \%$ of current nominal. Changing the value of the current flow through the LED affects the wavelength of the light emitted.

Therefore, PWM dimming is more suitable because rated current is applied to the LED at all times, changing only

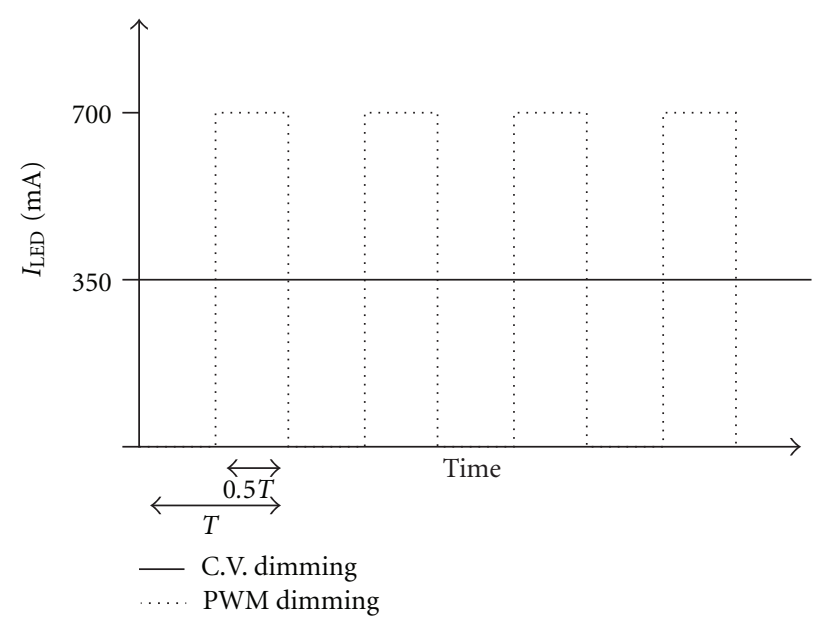

FIgURE 3: Waveforms of the current in the LED using the two methods dimming [1].

the fraction of time during which the current flows in each period (duty cycle) [1]. In a laboratory test, the amber color is imposed on a power LED supplied with constant current. The increase of junction temperature with $10^{\circ} \mathrm{C}$ determines a $5 \%$ decrease of the light flux, a reduction of the direct voltage of $20 \mathrm{mV}$, and a translation motion of the fundamental wavelength of $2 \mathrm{~nm}$ toward high wavelengths [23].

\section{Experimental Implementation}

Junction temperature directly affects the working performance of power LEDs. However, measurement of junction temperature is very difficult but can be found using the following calculation:

$$
T_{b}=\frac{T_{j}}{P \cdot R_{\theta_{j-b}}},
$$

where, $T_{b}$ is board temperature, $T_{j}$ is junction temperature, $P$ is LED power, and $R_{\theta_{j-b}}$ is thermal resistance from the junction to the board. There is a linear correlation between board temperature and junction temperature, as shown in (1) [24]. Moreover, the objective of the study is to investigate illuminance variation according to board temperature for single- and multichip power LEDs. Philips Luxeon K2 $3 \mathrm{~W}$, Samsung ceramic $5 \mathrm{~W}$, Coinlight-Ostar $10 \mathrm{~W}(2 \times 3$ matrix $)$, and Optagon $15 \mathrm{~W}(4 \times 4$ matrix $)$ single- and multichip power LEDs were used in the experiments. All of the LEDs have white $5400 \mathrm{~K}$ color temperature and they are shown in Figure 4.

Active and passive cooling was used for the experiments. A cooler material made from an aluminum alloy was used for passive cooling. The passive cooler dimensions were determined as approximately $5 \times 5 \times 5 \mathrm{~cm}$ for single-chip power LEDs and $12 \times 12 \times 5 \mathrm{~cm}$ for multichip power LED module according to their power supplies. A DC motor fan was coupled on the passive cooling element for active cooling. The DC motor fan was the same size as the passive cooling element. The active and passive coolers are seen in Figure 5 (Figure 5(a) for 10-15 W and Figure 5(b) for 3-5 W). 


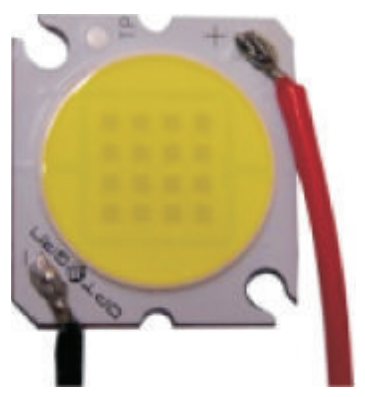

(a)

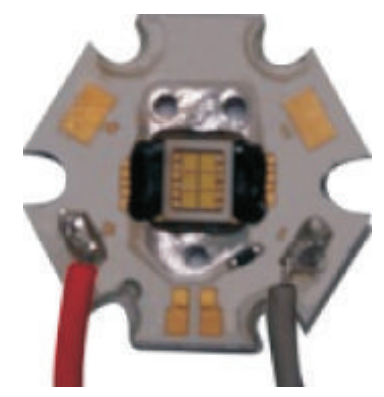

(b)

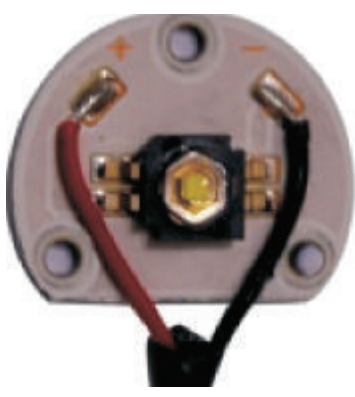

(c)

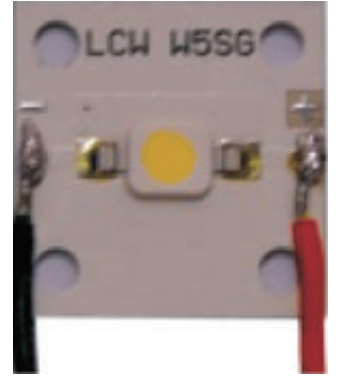

(d)

FIGURE 4: Single-chip and multichip Power LEDs used in experiments.

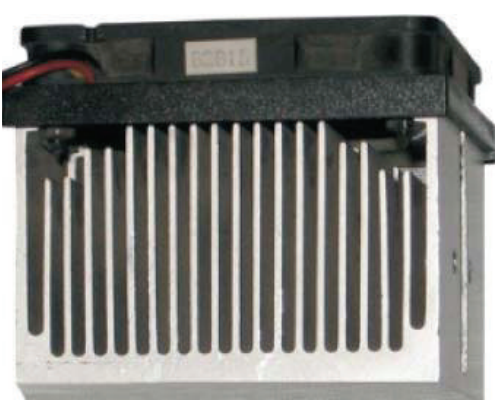

(a)

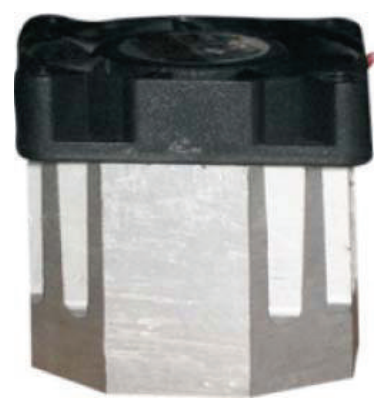

(b)

FIGURE 5: Passive and active coolers used in the experiments.

The designed PWM diver card (Figure 6) needs a $12 \mathrm{~V}$ DC power supply. The driver card has 2 digital inputs, one analog (4-20 mA) input (8 bit), 6 analog outputs, and 4 power outputs. PIC 16F876 was used as a system controller. The reference dim signal, which is in the range of $1 \mathrm{~V}(10 \%)-10 \mathrm{~V}(100 \%)$, is inserted to PIC through the 4-20 mA transducer circuit with a SAB 3013 DAC element. The dimming frequency is $350 \mathrm{~Hz}$ for the PWM method. Different outputs are designed to supply single- and multichip power LEDs in PWM driver cards.

Figure 7 illustrates the schematic of the experimental setup. The experimental test box, which is $60 \times 60 \times 60 \mathrm{~cm}$ in dimension, was painted with a matte-finish black paint to prevent reflection. Power LEDs were located on a $2 \mathrm{~cm}$ square circuit board. Then, they were attached to outside and top of the test box to prevent the effects of LED temperature. The room temperature was a constant $25^{\circ} \mathrm{C}$ during the experiments. Also, a $3 \mathrm{~cm}$ diameter aperture with a clear acrylic window in the bottom of the test box was created in the box to allow for illumination measurement using a lux meter. The board temperature values were measured by J-type thermocouple, which was connected to the cathode of power LEDs and recorded over regular time intervals. Maximum current was kept under $1050 \mathrm{~mA}$ during the experiments. 10 dim levels $(10 \%-100 \%)$ were set in a range of $0-1050 \mathrm{~mA}$, and then LED current, voltage, board temperature, and illuminance values were recorded for each level. Power LED operating temperature may also vary depending on time. Measured values are taken over an hour with five-minute intervals for each dim level due to the values reaching their steady-state values in this time range. For each dimming level and cooling condition, sixty values for one LED and nine-hundred-sixty values were recorded for all measurements.

Under the abovementioned conditions, firstly, CV dimming was applied to power LEDs with passive cooling and then to power LEDs with active cooling. Secondly, PWM dimming was applied to power LEDs with passive cooling and then to power LEDs with active cooling.

\section{Results and Discussion}

For general lighting, dim level is usually set to a range of $40 \%-80 \%$. Graphs are plotted for all dimming levels, but the range is taken into consideration to interpret graphs. However, graphs of obtained steady-state values from the experiments were shown here. Then, comparisons of conditions were made according to their average value of the graphs values.

The obtained board temperature graph for $15 \mathrm{~W}$ and $10 \mathrm{~W}$ multichip power LEDs with passive and active cooling under PWM and CV dimming is seen in Figures 8 and 9, respectively.

The board temperature for PWM dimming is about $40.3 \%$ lower than CV dimming with a passive cooler. Also, the board temperature for PWM dimming is about $43.6 \%$ lower than $\mathrm{CV}$ dimming values with an active cooler. 


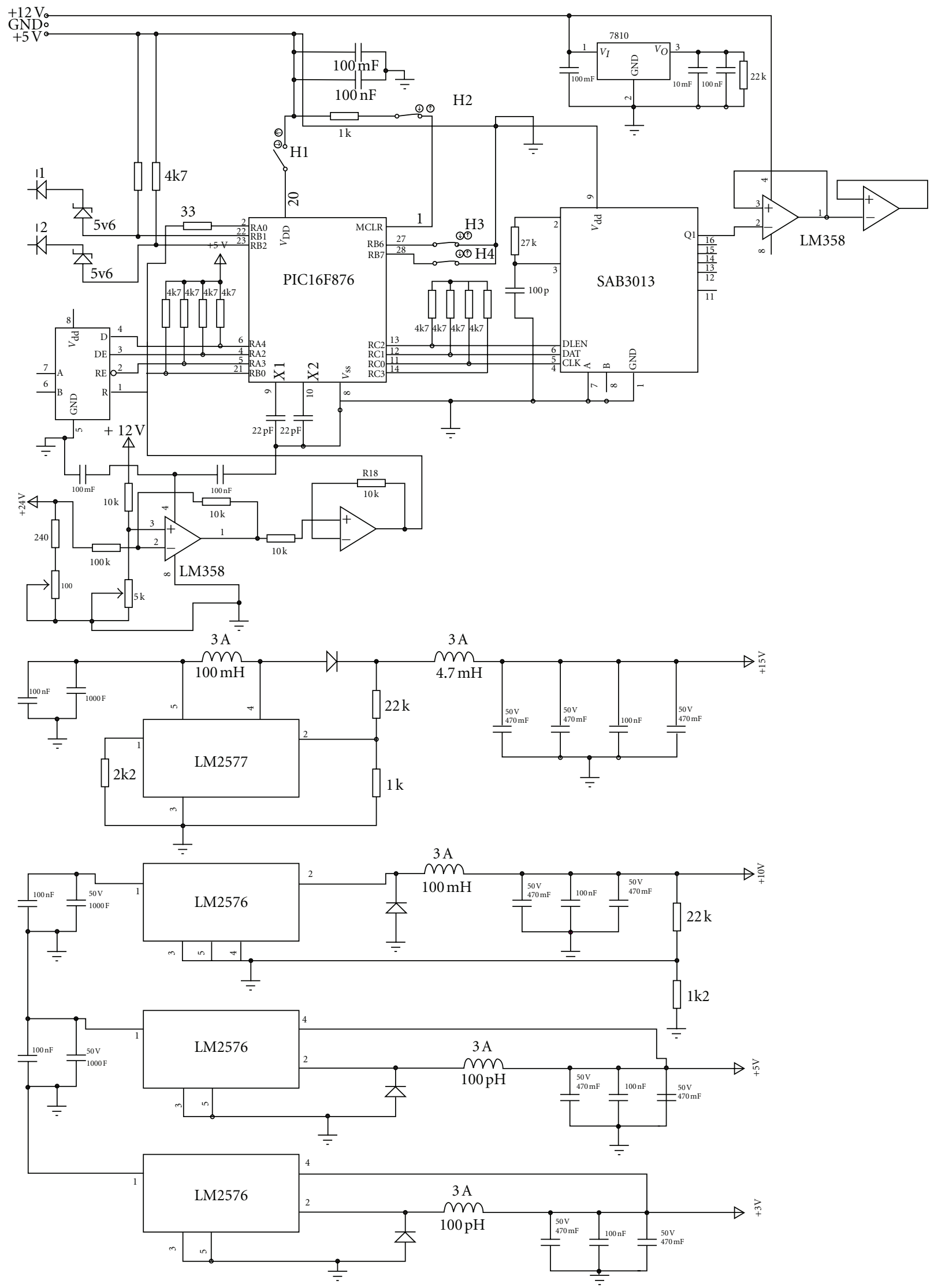

FIGURE 6: Designed PWM diver card scheme. 


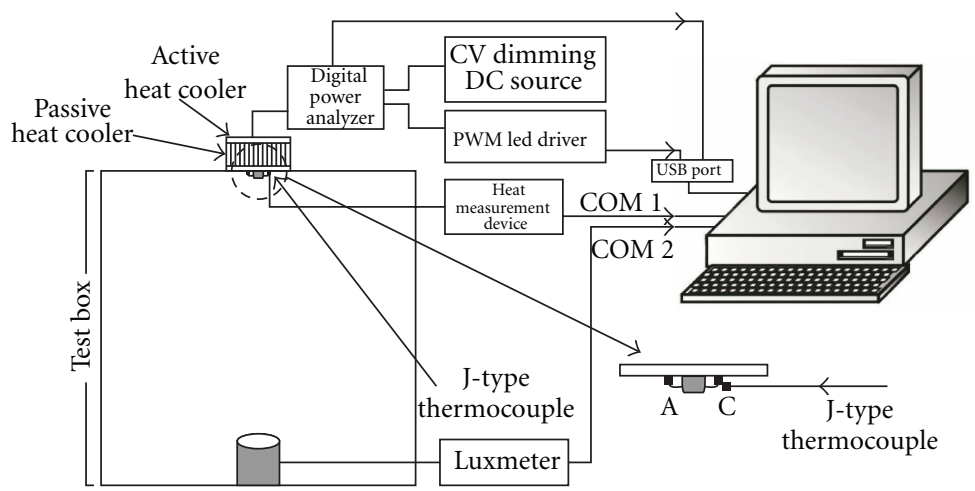

Figure 7: Schematic of the experimental setup.

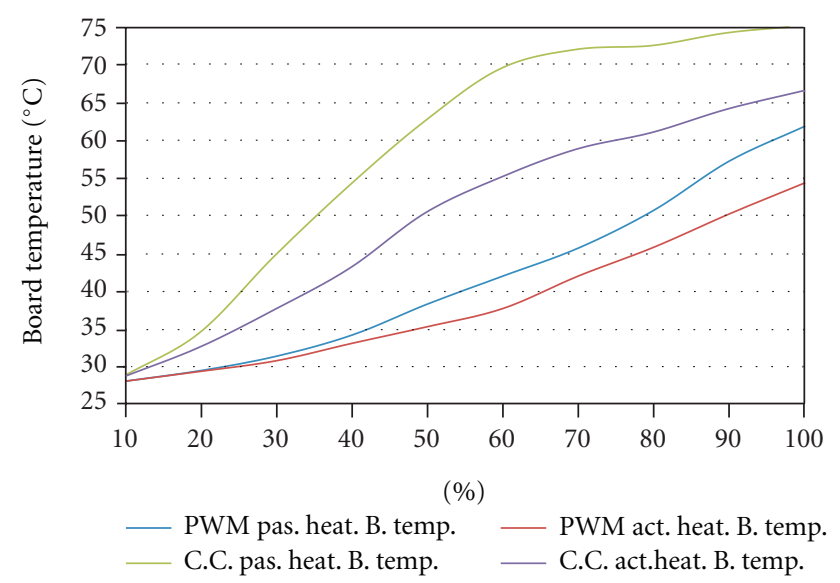

FIGURE 8: $15 \mathrm{~W}$ multichip power LED board temperature graph.

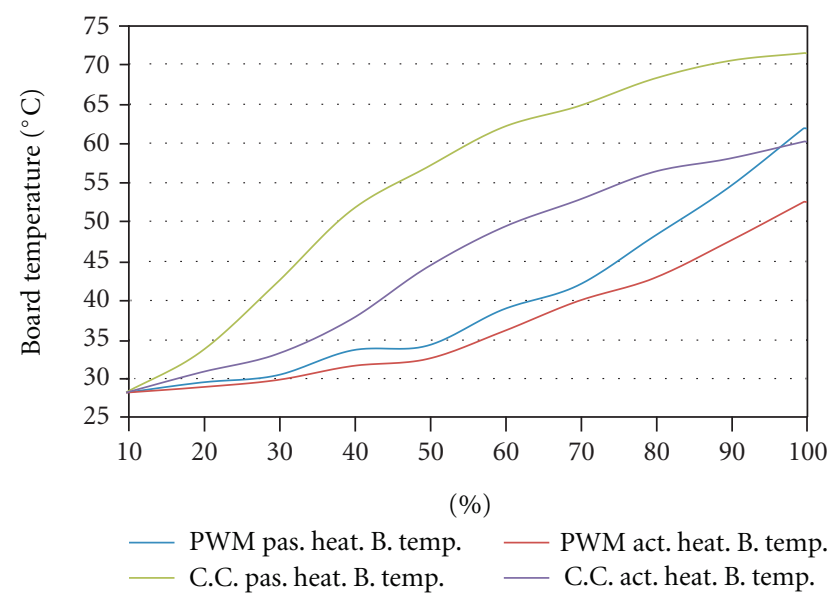

FIGURE 9: $10 \mathrm{~W}$ multichip power LED board temperature graph.

The obtained board temperature graph for single-chip power LEDs with passive and active cooling under PWM and $\mathrm{CV}$ dimming is seen in Figures 10 and 11, respectively.

According to the results, the board temperature for PWM dimming is about $21.3 \%$ lower than CV dimming with

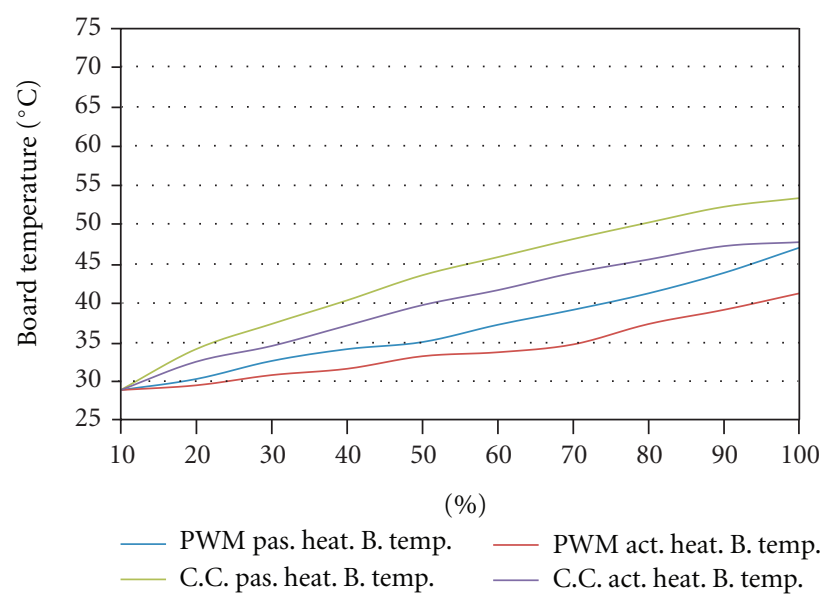

FIGURE 10: $5 \mathrm{~W}$ single-chip power LED board temperature graph.

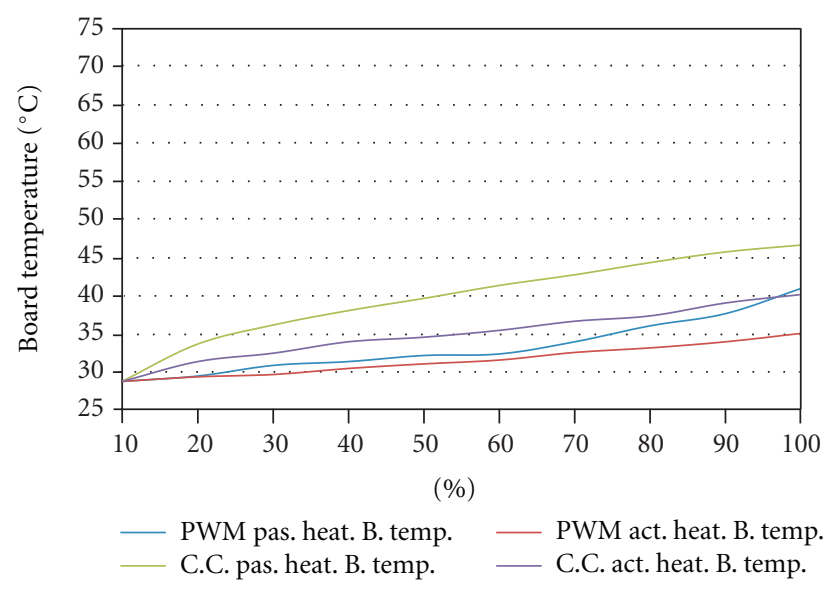

FIGURE 11: $3 \mathrm{~W}$ single-chip power LED board temperature graph.

a passive cooler. Also, the board temperature for PWM dimming is about $24.7 \%$ lower than CV dimming values with an active cooler.

As seen in Figures 12 and 13, illuminance values for the PWM dimming of multichip power LEDs with active 


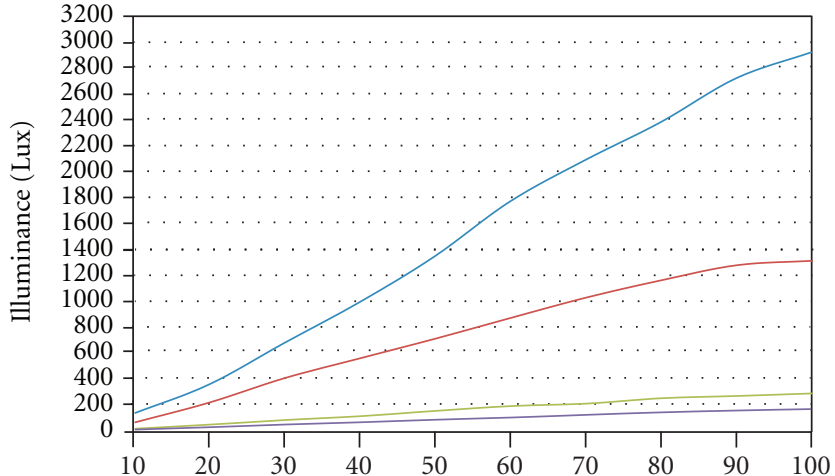

(\%)

$$
\begin{array}{ll}
-15 \mathrm{~W} \text { illuminance } & -10 \mathrm{~W} \text { illuminance } \\
-5 \mathrm{~W} \text { illuminance } & -3 \mathrm{~W} \text { illuminance }
\end{array}
$$

FIgURE 12: Passive cooling PWM experiments illuminance graph.

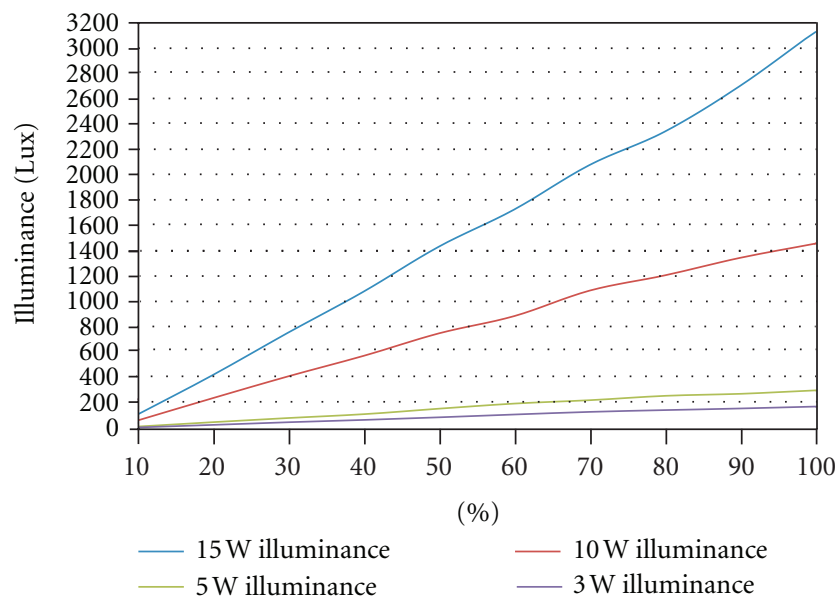

FIGURE 13: Active cooling PWM experiments illuminance graph.

cooling is about $7.4 \%$ higher than with passive cooling. This difference in illuminance values are about $24.7 \%$ for singlechip power LEDs.

The illuminance values for $\mathrm{CV}$ dimming with passive cooling and with active cooling are illustrated in Figures 14 and 15 , respectively.

The obtained illuminance values for CV dimming of multichip power LEDs with active cooling are about 6.5\% higher than with passive cooling. This difference in illuminance values is about $4.1 \%$ for single-chip power LEDs.

\section{Conclusion}

According to experimental results, PWM dimming has more advantages than $\mathrm{CV}$ dimming. In order to put forth these advantages, the data obtained from experiments will be interpreted under headings such as energy consumption, operating temperature, illuminance, and life of the material.

(i) The results for multichip power LEDs showed that PWM dimming consumes approximately $5.8 \%$ less

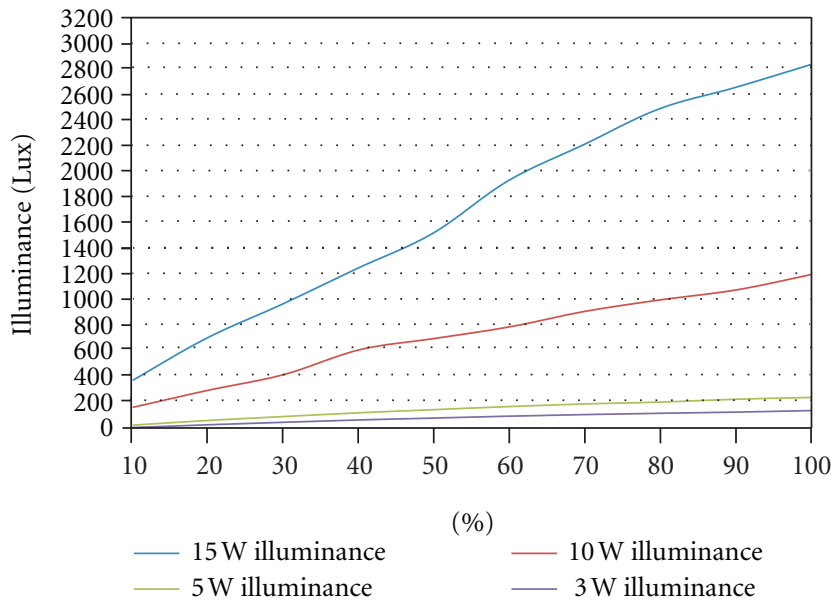

FIgure 14: Passive cooling CV dimming experiments illuminance graph.

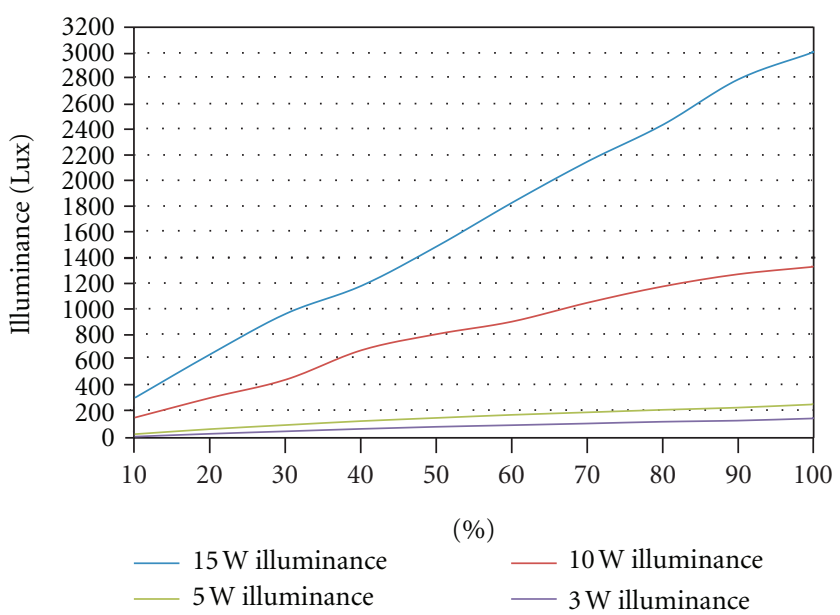

FIGURE 15: Active cooling CV dimming experiments illuminance graph.

power than $\mathrm{CV}$ dimming under the active cooling condition. However, PWM dimming values are about 3.7\% lower than CV dimming under the passive cooling condition. Moreover, PWM dimming values with active cooling are about $1.9 \%$ lower than with passive cooling; CV dimming values with active cooling are about $2.7 \%$ lower than with passive cooling. On the other hand, for single-chip power LEDs, PWM dimming values are approximately 3.3\% lower than $\mathrm{CV}$ dimming, under the active cooling condition. However, PWM dimming values are about $3.7 \%$ lower than CV dimming under the passive cooling condition. PWM dimming values with active cooling are about $0.9 \%$ lower than with passive cooling, while $\mathrm{CV}$ dimming values with active cooling are about $1.2 \%$ lower than with passive cooling.

(ii) The board temperature values of PWM dimming for multichip power LED modules are about $14 \%$ lower than CV dimming. However, board temperature 
values of PWM dimming for single-chip power LEDs are about $11 \%$ lower than CV dimming.

(iii) In terms of illuminance, PWM dimming values with active cooling for multichip power LEDs are about $7.4 \%$ higher than with passive cooling. The illuminance values of $\mathrm{CV}$ dimming with active cooling are about $6.5 \%$ higher than with passive cooling. These rates for single-chip power LEDs are about $4.8 \%$ higher.

(iv) Operating temperature is inversely proportional to lifetime for power LEDs. When the obtained data are analyzed, the operating temperature values of $\mathrm{CV}$ dimming are permanently higher than PWM dimming.

According to the results of this study, it is clear that when all power LEDs dim, PWM dimming must be used, especially for multichip power LED modules, for the desired illuminance values, and life time in catalog values due to their structure.

\section{References}

[1] W. A. Rodrigues, L. M. F. Morais, P. F. Donoso-Garcia, P. C. Cortizo, and S. I. Seleme, "Comparative analysis of power LEDs dimming methods," in Proceedings of the Power Electronics Conference (COBEP'11), pp. 378-383, November 2011.

[2] N. Onat, İ. Kıyak, and G. Gökmen, "Experimental wavelet packet transient-state analysis of electrical machines directly fed by photovoltaic cells," International Review of Electrical Engineering, vol. 5, no. 5, pp. 2081-2087, 2010.

[3] İ. Kiyak, V. Topuz, and B. Oral, "Modeling of dimmable High Power LED illumination distribution using ANFIS on the isolated area," Expert Systems with Applications, vol. 38, no. 9, pp. 11843-11848, 2011.

[4] İ. Kiyak, B. Oral, and V. Topuz, "Design and comparative analysis of high power led with fluorescent lamp in laboratory lighting systems," Energy Education Science and Technology Part A, vol. 29, no. 2, pp. 1147-1158, 2012.

[5] İ. Kiyak, V. Topuz, and B. Oral, "Modeling of high power led illumination distribution using ann," in Proceedings of the 6th International Conference on Electrical and Electronics Engineering (ELECO'09), pp. II137-II141, Bursa, Turkey, November 2009.

[6] J. Li, B. Ma, R. Wang, and L. Han, "Study on a cooling system based on thermoelectric cooler for thermal management of high-power LEDs," Microelectronics Reliability, vol. 51, no. 12, pp. 2210-2215, 2011.

[7] J. H. Choi and M. W. Shin, "Thermal investigation of LED lighting module," Microelectronics Reliability, vol. 52, no. 5, pp. 830-835, 2012.

[8] B. J. Huang and C. W. Tang, "Thermal-electrical-luminous model of multi-chip polychromatic LED luminaire," Applied Thermal Engineering, vol. 29, no. 16, pp. 3366-3373, 2009.

[9] W. Wei, J. Su, D. Shen, B. Zhang, and L. Peng, "Automatic temperature monitoring and constant current driving high power led supplied by PV/wind/grid hybrid system," in Proceedings of the IEEE The 10th International Conference on Electronic Measurement \& Instruments (ICEMI'11), pp. 294298, Chengdu, China, August 2011.
[10] A. Gago-Calderón, J. Fernández-Ramos, and L. Narvarte, "Temperature-controlled light-emitting diode lamp for photovoltaicrural applications," Progress in Photovoltaics: Research and Applications. In press.

[11] N. Onat, "Recent developments in maximum power point tracking technologies for photovoltaic systems," International Journal of Photoenergy, vol. 2010, Article ID 245316, 11 pages, 2010.

[12] M. Fathi, A. Aissat, and M. Abderrazak, "Optimization of the electronic driver and thermal management of LEDs lighting powered by solar PV,' Energy Procedia, vol. 18, pp. 291-299, 2012.

[13] X. Lu, T. C. Hua, and Y. P. Wang, "Thermal analysis of high power LED package with heat pipe heat sink," Microelectronics Journal, vol. 42, no. 11, pp. 1257-1262, 2011.

[14] A. Christensen and S. Graham, "Thermal effects in packaging high power light emitting diode arrays," Applied Thermal Engineering, vol. 29, no. 2-3, pp. 364-371, 2009.

[15] C. J. Weng, "Advanced thermal enhancement and management of LED packages," International Communications in Heat and Mass Transfer, vol. 36, no. 3, pp. 245-248, 2009.

[16] L. Yin, L. Yang, W. Yang et al., "Thermal design and analysis of multi-chip LED module with ceramic substrate," Solid-State Electronics, vol. 54, no. 12, pp. 1520-1524, 2010.

[17] T. Cheng, X. Luo, S. Huang, and S. Liu, "Thermal analysis and optimization of multiple LED packaging based on a general analytical solution," International Journal of Thermal Sciences, vol. 49, no. 1, pp. 196-201, 2010.

[18] T. Yakhanthip, N. Kungwan, J. Jitonnom, P. Anuragudom, S. Jungsuttiwong, and S. Hannongbua, "Theoretical investigation on the electronic and optical properties of poly(fluorenevinylene) derivatives as light-emitting materials," International Journal of Photoenergy, vol. 2011, Article ID 570103, 9 pages, 2011.

[19] Y. Lin, Y. Lu, Y. Gao, Y. Chen, and Z. Chen, "Measuring the thermal resistance of LED packages in practical circumstances," Thermochimica Acta, vol. 520, no. 1-2, pp. 105-109, 2011.

[20] M. S. Wu, H. H. Huang, B. J. Huang, C. W. Tang, and C. W. Cheng, "Economic feasibility of solar-powered led roadway lighting," Renewable Energy, vol. 34, no. 8, pp. 1934-1938, 2009.

[21] L. Kim, W. J. Hwang, and M. W. Shin, "Thermal resistance analysis of high power LEDs with multi-chip package," in Proceedings of the IEEE 56th Electronic Components and Technology Conference, pp. 1076-1081, San Diego, Calif, USA, June 2006.

[22] İ. Kiyak, B. Oral, and V. Topuz, "Effects of lighting performance on cooling for power led," in Proceedings of the 11th European Lighting Conference (LUX EUROPA'09), pp. 833840, İstanbul, Turkey, September 2009.

[23] R. Faranda, S. Guzzetti, G. C. Lazaroiu, and S. Leva, "Refrigerating liquid prototype for LED's thermal management," Applied Thermal Engineering, vol. 48, pp. 155-163, 2012.

[24] L. Jayasinghe, Y. Gu, and N. Narendran, "Characterization of thermal resistance coefficient of high-power LEDs," in 6th International Conference on Solid State Lighting, vol. 6337 of Proceedings of SPIE, New York, NY, USA, August 2006. 


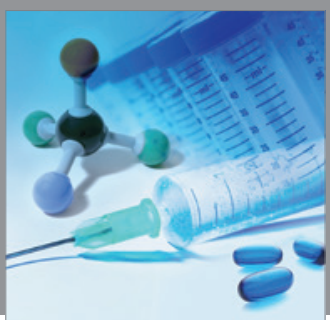

International Journal of

Medicinal Chemistry

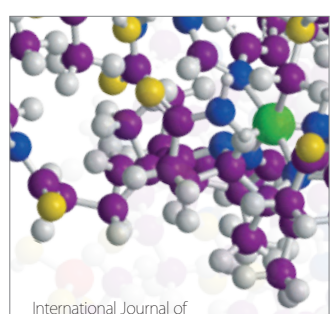

Carbohydrate Chemistry

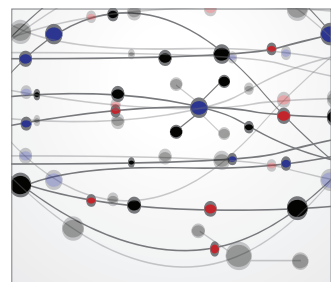

The Scientific World Journal
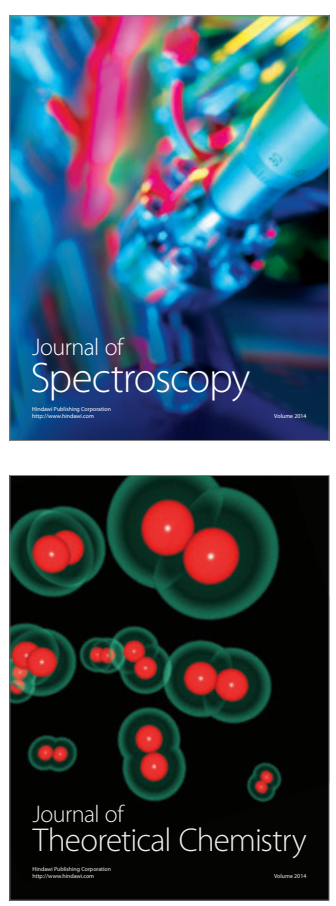
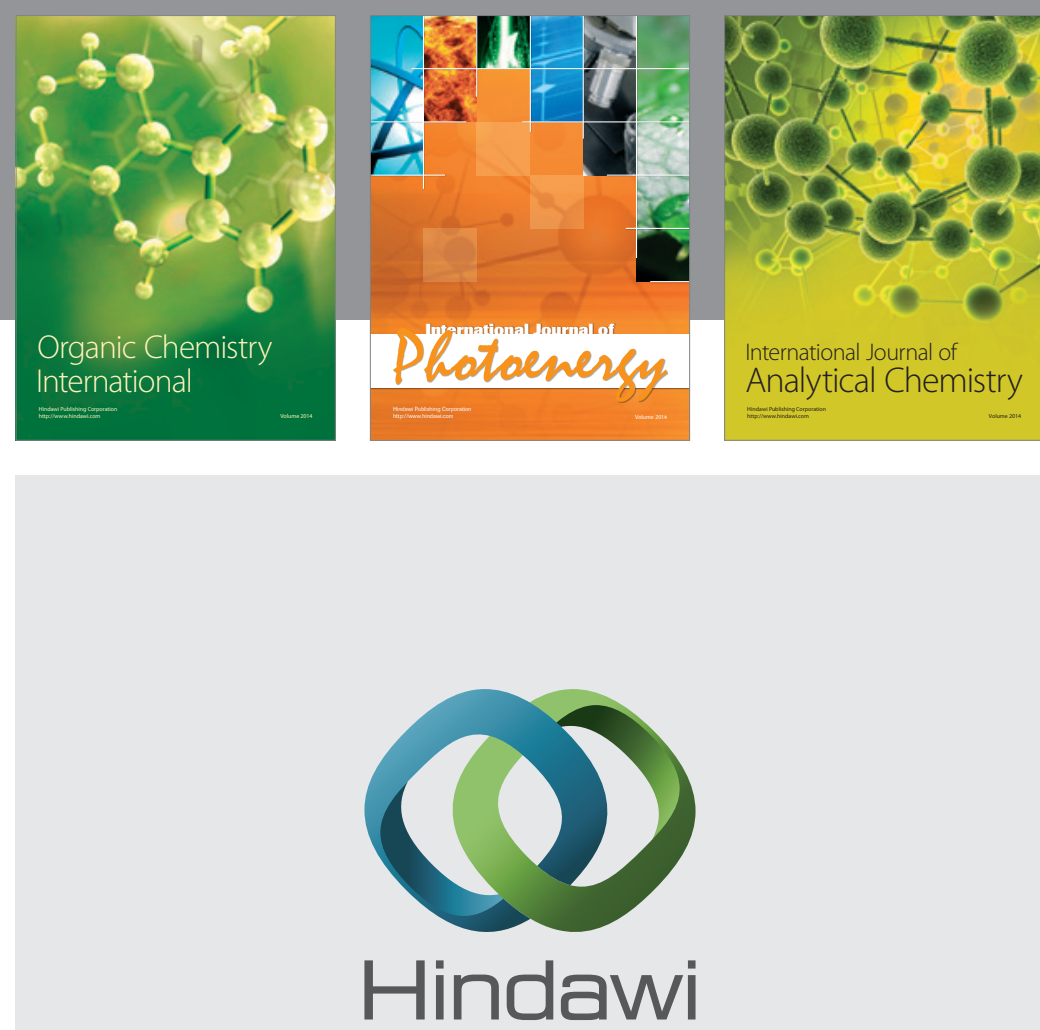

Submit your manuscripts at

http://www.hindawi.com
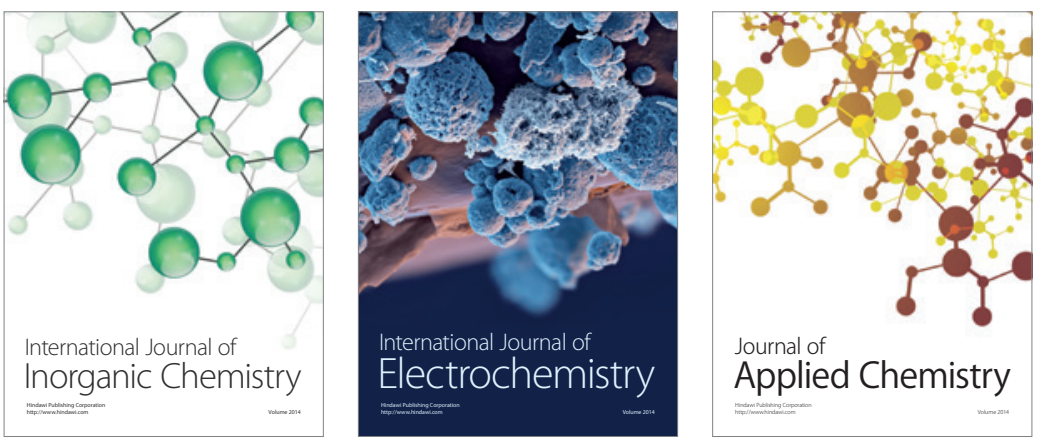

Journal of

Applied Chemistry
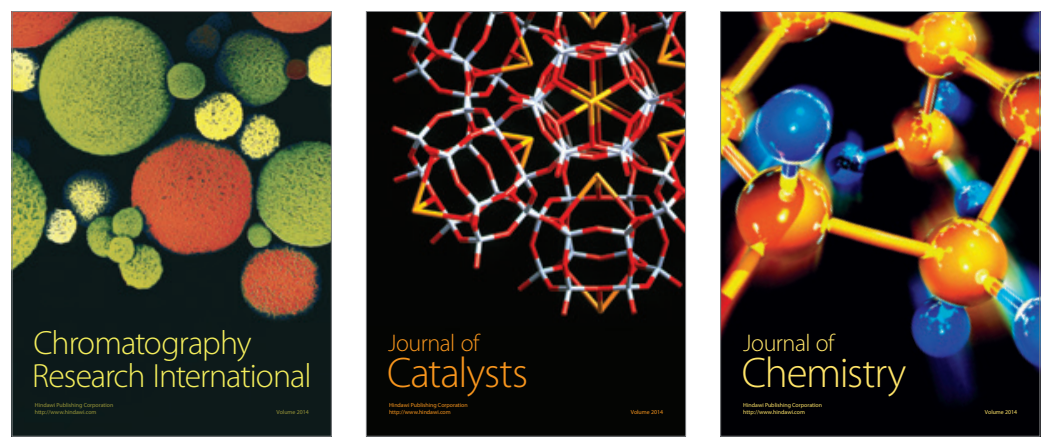
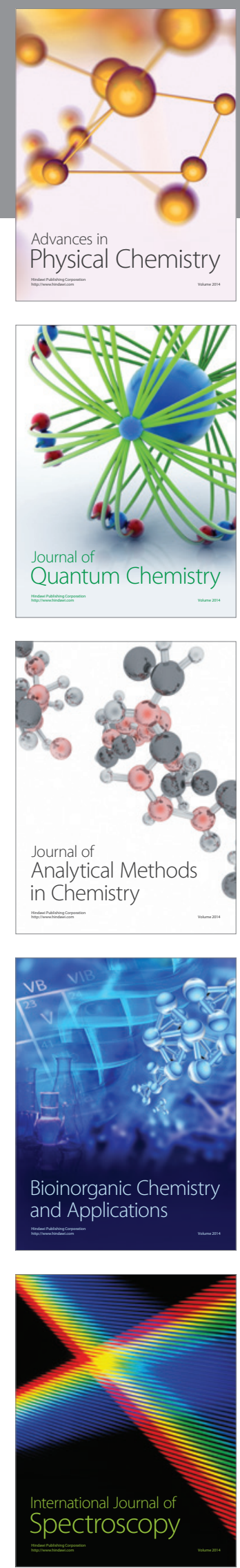